\title{
CRISES AS FACTORS MOTIVATING CHANGES IN CREATING PUBLIC POLICY IN THE EUROPEAN COMMUNITIES / EUROPEAN UNION
}

\begin{abstract}
The purpose of this text is to present the results of a research in which the author analysed succeeding crisis situations that could constitute the basis for some of the changes in the political system of the EC/EU and subsequently made an attempt to delineate a certain scheme behind such behaviours. It is justified to seek the answer to the following question: What is the underlying reason for introducing changes in such situations and is it possible to pinpoint certain shared elements in different cases?

To achieve that goal the author takes a closer look on the "empty chair" crisis, Schengen Area crisis and the recent financial crisis in Europe. In order to confirm the actual value of the conducted research, the author will make an attempt to relate his observations to the current geopolitical situation in Eastern Europe with reference to the EU competences in the existing political system.
\end{abstract}

\section{Key words}

European Union, public policy, multilevel system, systemic crisis, financial crisis in Europe, Ukraine

\section{Introductory remarks}

The process of European integration is a specific collision of opposing tendencies in economic cooperation and political independence of its participants - the nation states. The EC/EU continues to develop. The success and benefits arising from an increased international cooperation seem to far exceed the initial beliefs and, at the same time, they are the source of new needs.

* Radosław Potorski is a member of the expert group TEAM EUROPE by the European Commission Representation in Poland. He performs the function of the Social Advisor of the Chairman of the Sejm Commission for European Union Affairs. 